\title{
The Concept of Medicalisation Reassessed
}

Medicalisation has been an important concept in sociological discussions of medicine since its adoption by medical sociologists in the early 1970s. Yet it has been criticised by some sociologists, in part because it seems too negative about medicine, and modified or replaced by others with concepts deemed more relevant like biomedicalisation and pharmaceuticalisation. My aim in this paper is to reassess the concept and consider whether it still has value in exploring significant aspects of the role of medicine in present-day society. I start with an archaeology of the concept's development and the different ways it has been used. This covers some familiar ground but is essential to the main task: examining criticisms of the concept and assessing its value. I conclude that the concept continues to have a crucial and vibrant place in sociological analyses of medicine and that the process of medicalisation is still a key feature of late-modern social life and culture.

The concept's introduction

The first use of the concept is usually identified as an encyclopaedia entry by the American sociologist, Jesse Pitts (1968), on 'social control', a term then widely used by sociologists of deviance to refer to the social processes involved in regulating the behaviour of individuals and groups. Pitts argued that 'redefining certain aspects of deviance as illness rather than crime' (1968:390) is one means whereby deviant behaviour is controlled, adding 'medicalization is one of the most effective means of social control' (1968:391). Thus he suggested that precisely what counts as illness is socially constructed and a product of social factors (Conrad and Barker 2010). Pitts drew on the work of his teacher, Talcott Parsons (1951), who viewed medicine as a mechanism of social control analysing the norms governing the 'sick role', which provides one way of channelling deviant motivations. Pitts attributed medicalisation to the diffusion of Freudian ideas about unconscious motivations into understandings of deviance, judging the process to have both advantages and disadvantages: 'social control becomes more humane and forgiving, but perhaps also more relentless and pervasive' (1968:391).

Irving K. Zola expressed similar ideas in his classic 'Medicine as an institution of social control' (1972), the first medical sociology paper to use the term, its title echoing Pitts's analysis. Zola argued that medicine was beginning to replace religion and law as a major institution of social control: 'It is becoming the new repository of truth, the place where absolute and often final judgements are made by supposedly morally neutral and objective experts' (1972:487). In his view medical involvement did not remove the matter from issues of morality or individual responsibility, though the appearance of neutrality was one of medicine's attractions. 
Zola defined medicalisation as the process of "making medicine and the labels "healthy" and "ill" relevant to an ever increasing part of human existence' (1972:487; his emphasis), suggesting as had Pitts, that illness is socially defined or 'constructed'. This definition allows that medicine can become relevant to new areas without necessarily deploying the labels health and illness - the suffix 'isation' indicating a process, a series of changes, as with terms like democratisation, modernisation, and globalisation. Zola identified four dimensions of medicalisation. First, 'The expansion of what in life is deemed relevant to the good practice of medicine' (1972:493). Multi-causal models of disease, he argued, encourage doctors to consider many aspects of the lives of those seeking help (though doctors have long advised on matters like diet, sleep, and hygiene). Second, 'the retention of absolute control over certain technical procedures' (1972:494) illustrated by the work of plastic surgeons in improving physical appearance (often focused on bodily enhancement not illness), and the increased prescribing of medications, including for treating psychosocial states. Third, medicine's 'near absolute access to certain “taboo" areas', and 'almost exclusive licence' (1972:495) to treat the workings of mind and body:

In a sheer statistical sense the import of this is especially great if we look at only four such problems - ageing, drug addiction, alcoholism and pregnancy. The first and last were once regarded as normal natural processes and the middle two as human foibles and weaknesses. Now this has changed and to some extent medical specialities have emerged to meet these new needs. Numerically this expands medicine's involvement not only in a longer span of human existence, but it opens the possibility of medicine's services to millions if not billions of people (1972:495-96).

The final dimension was 'the expansion of what in medicine is deemed relevant to the good practice of life' (1972:496).

Eliot Freidson's classic text, The Profession of Medicine (1970), itself responding to Parsons's (1951) analysis of medicine, and published at a time when medical power was considerable, was a key influence on Zola's thinking, though Freidson did not talk of medicalisation. Zola quoted his assertion that 'the medical profession has first claim to the jurisdiction over the label of illness and anything to which it may be attached, irrespective of its capacity to deal with it effectively' (1970:251).

However, Zola made it clear that he did not view medicalisation as the product of professional 'imperialism', that is medical empire-building, arguing that this would lead people 'to think of the issue in terms of misguided human efforts or motives' (1972:487). Rather it is 'rooted in our increasingly complex technological and bureaucratic system - a system which has led us down the path of the reluctant reliance on the expert' (ibid). Zola was therefore primarily describing a social process and not seeking to explain it beyond this brief reference to certain changes in the character of society. He also stated that his paper was 'not an attack on medicine so much as on a situation in which we find ourselves in the latter part of the twentieth century'

(1972:502). He was, however, concerned about medicalisation's consequences, commenting that the labels of health and illness 
'are remarkable "depoliticizers" of an issue' (1972:500) closing off other types of intervention. Hence, like Pitts, he added an evaluation of medicalisation.

Zola's view that activities by doctors did not explain the extension of the medical terrain was something of a departure from Parsons and Freidson, who both indicated ways in which medicine's ideas and practices could contribute to the extension.

Parsons's discussion of surgeons' decisions about whether to operate in situations of uncertainty pointed to their bias towards active intervention, often encouraged by families and patients:

Within this situation there is a variety of motivational factors operating to drive action in one direction, namely, "success" of the therapeutic enterprise. The physician himself is trained and expected to act, not merely to be a passive observer of what goes on. The patient and his family are also under strong emotional pressures to "get something done" (1951:466).

Freidson, however, went a step further suggesting that doctors search for new illnesses actively contributing to medicine's expanding role:

Clearly, neither medicine nor the physician may be characterized as passive. As a consulting rather than scholarly or scientific profession, medicine is committed to treating rather than merely defining and studying man's ills. It has a mission of active intervention guided by what, in whatever time or place it exists, it believes to be ill in the world. Furthermore, it is active in seeking out illness. The profession does treat the illnesses layman take to it, but it also seeks to discover illness of which laymen may not even be aware. One of the greatest ambitions of the physician is to discover and describe a 'new' disease or syndrome and to be immortalized by having his name used to identify the disease $(1970: 252)$

The approach of Parsons and Freidson was analytical and non-judgemental. This detachment was not true of Ivan Illich, a

Catholic priest, social theorist, and activist, who in Medical Nemesis: The expropriation of health (1975) was highly critical of both medicine and medicalisation. The book opened with the provocative claim 'The medical establishment has become a major threat to health' adding 'A professional and physician-based health care system' has 'grown beyond tolerable bounds' (1975:11). Medicine, he argued, generates illness through clinical iatrogenesis, such as useless medical treatments and doctorinflicted injuries (though long-recognised, its extent is debated); through social iatrogenesis, encompassing the medicalisation of life; and through structural iatrogenesis, which covers the ways medicine encourages dependence, undermining people's capacity to cope with pain and suffering by transforming them into technical problems. Medicalisation, which he did not define, was evidenced by increases in healthcare spending and prescribed medications, medicine's growing involvement in birth and death, the focus on preventing sickness, and rising public expectations of 'medical breakthroughs'. Like Zola, Illich therefore used the term to describe the extension of medicine's activities, but unlike him was a strident critic of medicine.

Illich also talked of 'medical colonization' (1975:11), but this was an alternative to the term medicalisation and should not be taken to suggest that he viewed doctors as playing an active role in empire-building. Instead, influenced by ideas from political economy and Marxist thinking, he attached major importance to production, contending that medicalisation was a 'by- 
product of an over-industrialized society' (1975:61), and 'one aspect of the destructive dominance of industry' (ibid). Critical of technocratic elites, Illich attributed overriding importance to individual freedom and autonomy.

Peter Conrad is now the leading sociological exponent of the concept, his writings on medicalisation dating back to the 1970 s. In a 1975 paper he examined the introduction of hyperkinesis (now attention deficit hyperactivity disorder (ADHD)) as an instance of the medicalisation of deviance (children given the new diagnosis had previously mostly been viewed as disruptive and naughty). He described medicalisation as the process of 'defining behavior as a medical problem or illness and mandating or licensing the medical profession to provide some type of treatment for it' (1975:12), later arguing (1992) that defining behaviour in medical terms, not medical jurisdiction, is the key aspect of medicalisation - a definition reflecting his social constructionist orientation.

Conrad attributed the emergence of the category of hyperkinesis primarily to two factors: the pharmaceutical 'revolution', with the growth of psychoactive drugs and their promotion for childhood disorders (psychostimulants like Ritalin were already on the market); and government action. Conrad noted two government reports on treating school children with psychostimulants, arguing that whilst the reports sought to ensure the drugs were appropriately used under medical supervision, nonetheless they 'served as blue ribbon approval for treating hyperkinesis with psychoactive medications' (1975:15-16). However, he also commented 'The medical profession may not have entirely sought this role, but its members have been, in general, disturbingly unconcerned and unquestioning in their acceptance of it' (1975:20). And, while not claiming active medical imperialism, he suggested the indirect role of medicine, arguing that alongside the impact of scientific developments in pharmacology and genetics, the use of new treatments for hyperkinesis was 'encouraged by the prestige of the medical profession and its attachment to science' (1975:18). Later, when further examining the factors underpinning medicalisation (2005; 2007; 2013), he argued that its 'engines' are 'shifting from the medical profession, interprofessional or organisational contests and social movements and interest groups to biotechnology, consumers, and managed-care organizations' (2007:142), though his earlier explanation for the medicalisation of hyperkinesis had given considerable attention to biotechnology, particularly the pharmaceutical industry, and only a limited role to the medical profession.

Conrad also considered the implications of medicalisation, starting with its benefits:

Clearly there are some real humanitarian benefits to be gained by such a medical conceptualization of deviant behaviour. There is less condemnation of the deviants (they have an illness, it is not their fault) and perhaps less social stigma. In some cases, even the medical treatment itself is more humanitarian social control than the criminal justice system (1975:18). 
He then listed four negative consequences. First, 'The problem of expert control', which removes a problem 'from the public realm where there can be discussion by ordinary people' (ibid). Second, 'Medical social control', which 'allows certain things to be done that otherwise could not be considered' (ibid), including treatment with psychoactive drugs. Third, 'The individualization of social problems' that directs people 'to look for causes and solutions to complex social problems in the individual rather than in the social system' (1975:19); this means individuals are expected to change, not social institutions and practices. Finally, echoing Zola, he refers to 'The depoliticization of deviant behaviour' (ibid) resulting from this individualisation.

A different theoretical approach to medicalisation was developed by French social theorist and historian Michel Foucault. In an essay on social (public health) medicine he identified medicalisation as one of three key features of social medicine's history contending that 'starting in the eighteenth century human existence, human behavior, and the human body were brought into an increasingly dense and important network of medicalization that allowed fewer and fewer things to escape' ([1974]2000:135),. And in his History of Sexuality, he talked of 'The medicalization of the sexually peculiar' ([1976]1978:44). At this stage he used the term to suggest medical power and authority. However, his developing ideas about 'disciplinary power' and 'governmentality' (1991) were adopted by other authors replacing earlier ideas about social control, For Foucault disciplinary power, despite the concept's repressive connotations, is also productive and engaged in constituting and creating bodies.

Table 1 presents the key features of these early ideas about medicalisation.

Table 1: Early ideas about medicalisation

\begin{tabular}{|l|l|l|l|}
\hline Author & Defining features & Explanatory factors & Consequences \\
\hline $\begin{array}{l}\text { Pitts } \\
(1968)\end{array}$ & $\begin{array}{l}\text { Control of deviant behaviour by } \\
\text { medicine. }\end{array}$ & Spread of Freudian thinking. & $\begin{array}{l}\text { More humane and forgiving, but more } \\
\text { relentless. }\end{array}$ \\
\hline $\begin{array}{l}\text { Zola } \\
(1972)\end{array}$ & $\begin{array}{l}\text { Making medicine and the labels health } \\
\text { and illness relevant to an increasing part } \\
\text { of human life. }\end{array}$ & $\begin{array}{l}\text { Technological and bureaucratic } \\
\text { system. }\end{array}$ & $\begin{array}{l}\text { Appears to lift moral responsibility from } \\
\text { the individual, but does not. } \\
\text { Depoliticises issues closing off other } \\
\text { types of intervention. }\end{array}$ \\
\hline $\begin{array}{l}\text { Illich } \\
(1975)\end{array}$ & $\begin{array}{l}\text { Not defined; medical colonisation is an } \\
\text { alternative. Evidenced by increased } \\
\text { healthcare spending, dependence on } \\
\text { drugs, the medicalisation of the life } \\
\text { span, etc. }\end{array}$ & $\begin{array}{l}\text { Product of an over-industrialised } \\
\text { society. }\end{array}$ & $\begin{array}{l}\text { Threat to health; undermines families' } \\
\text { and individuals' capacity to care for } \\
\text { sickness, pain and suffering. }\end{array}$ \\
\hline $\begin{array}{l}\text { Conrad } \\
(1975)\end{array}$ & $\begin{array}{l}\text { Defining behaviour as a medical } \\
\text { problem and mandating the medical } \\
\text { profession to provide treatment. }\end{array}$ & $\begin{array}{l}\text { Pharmaceutical revolution; } \\
\text { government action; medicine's } \\
\text { prestige and attachment to } \\
\text { science. }\end{array}$ & $\begin{array}{l}\text { Can be more humanitarian, but removes } \\
\text { problem from public realm into hands of } \\
\text { experts; individualises and depoliticises } \\
\text { social problems. }\end{array}$ \\
\hline $\begin{array}{l}\text { Foucault } \\
(1974 ; \\
1976)\end{array}$ & $\begin{array}{l}\text { Bringing more aspects of the human } \\
\text { body and behaviour into medical } \\
\text { practice and discourse. }\end{array}$ & $\begin{array}{l}\text { Regimes of power and } \\
\text { knowledge; bio-politics. }\end{array}$ & $\begin{array}{l}\text { Constitutes our ways of thinking, how } \\
\text { we experience ourselves, and is creative } \\
\text { as well as repressive }\end{array}$ \\
\hline
\end{tabular}




\section{Using the concept}

Concepts can be viewed as tools that provide users with ways of understanding the world, and ideas about medicalisation and medical control were quickly and extensively adopted. Here I explore their use by three diverse, sometimes overlapping, groups: feminists; Focauldians; and critics of psychiatry.

Feminists

The idea of increasing medical control, often viewed as unacceptable and not restricted to deviance, was explored in the 1970s by feminists from diverse academic backgrounds, some explicitly talking of medicalisation. The key concern was the power doctors (still then usually male) exercised over women in relation to matters such as menstruation, birth control, pregnancy, abortion, and childbirth. For example, Barbara Ehrenreich and Deirdre English produced two pamphlets, Witches, Midwives and Nurses (1972) and Complaints and Disorders (1973), in which they argued that women's role as healers had been undermined and that medicine reinforced expectations that women should be confined to their roles of wives and mothers. Yet the authors recognised some significant gains: 'The medical system is strategic for women's liberation. It is the guardian of reproductive technology - birth control, abortion, and the means for safe childbirth' (1973:9). In For Her Own Good: 150 years of the experts' advice to women (1979) they further developed these ideas, though here the benefits were less emphasised and the focus was on the 'ascent' and 'reign' of experts (psychologists, psychoanalysts, sociologists, and doctors), along with the pathologising of motherhood and the sexual politics of sickness. Experts, especially doctors, were contributing to women's subordination from which they struggled to free themselves.

Similar themes were explored by other feminists. Michele Barrett and Helen Roberts (1978) examined women's experience of general practice and its reinforcement of gender roles using the concept of medicalisation. So, too, did Ann Oakley (1984) in her history of the medical care of pregnant women. Childbirth was one of several areas considered by Catherine Riessman (1983) when examining women and medicalisation, and by other authors (eg Barker 1998). Hilary Allen in Justice Unbalanced: Gender, psychiatry and judicial decisions (1987) analysed the medicalisation of criminality in women, while others examined the expanding role of medicine in relation to menstruation and infertility. For instance, Susan Bell (1986) analysed the medicalisation of the menopause, Paula Caplan and colleagues (1992) raised questions about whether 'premenstrual syndrome' should be deemed a psychiatric disorder, Anne V Bell (2009) explored working class women's experiences of medicalised infertility and Kuntala Lahiiri-Dutt (2015) the medicalising of menstrual hygiene in South Asia. 
Numerous writers have been influenced by Foucauldian ideas about medicalisation, medical surveillance and biopower. David Armstrong in The Political Anatomy of the Body (1983) drew on Foucault's The Birth of the Clinic ([1963]1973) to explore the 'medical gaze' in British twentieth-century medicine. And Nikolas Rose, examining twentieth-century developments in psychiatry, viewed the move away from mental hospitals in terms of a proliferation of specialised sites of psychiatric activity, arguing that 'Psychiatry provides us with the very terms in which our problems are constituted, through its elaboration of the norms and images of healthy mental life, and its characterization of the features of pathology' (1986:43), thereby emphasising the cultural impact of psychiatric ideas. In another he talked of the 'medicalization of social space' (1994:64) and of nineteenth century campaigns 'to medicalize the family' (1994:66), referring again to the way in which medicine permeates people's lives and understandings:

And in the very same movement as illness becomes amenable to an explanation in terms of the biology of the body, medical experts come to take up their role as masters of lifestyle. In the subsequent search for a normality conceived in terms of health, we have come to experience ourselves and our lives in fundamentally medical terms (1994:69).

Subsequently, in a paper critical of the concept, he asserted 'The practices of medicine have modified the very life form that is the contemporary human being' (2007:700) and 'Medicine is inextricably intertwined with the ways in which we experience and give meaning to our world' (2007:701), suggesting a penetration of medicine into daily life even more fundamental than Illich had outlined.

\section{Critics of psychiatry}

Thomas Szasz's broad and forceful critique of psychiatry developed in The Myth of Mental Illness (1961) and numerous other books, and his conceptualisation of most mental illness as 'problems of living', was an early influence on sociological thinking about the medicalisation of mental and behavioural deviance. Subsequent research has mainly focused on the development and transformation of specific psychiatric disorders. For example, Conrad's 1975 paper on hyperkinesis offered an empirical case study of one mental disorder, and his subsequent research several others. Deviance and Medicalization (1980a) with Joseph Schneider covered issues such as homosexuality (removed from the Diagnostic and Statistical Manual (DSM) at the end of 1973 and officially demedicalised), and alcoholism - the latter a case where Alcoholics Anonymous played a key role in the medicalisation process. And with Potter (2000) he examined the extension of the category of ADHD to adults. In turn the anthropologist Allan Young in The Harmony of Illusions: Inventing post-traumatic stress disorder viewed the disorder as a 
cultural product 'glued together by the practices, technologies, and narratives with which it is diagnosed, studied, treated and represented' (1995:5), and discussing traumatic memory referred to 'the medicalization of the past' (1995:39).

Others have analysed how psychiatry has transformed differences in behaviour and feelings previously considered normal into mental pathology, Conrad talking of 'The pathologization of everything' (2007:148). Susie Scott (2007) explored the medicalisation of shyness, an aspect of personality now redefined as social phobia (social anxiety disorder), while Christopher Lane (2007) examined the same transformation giving considerable attention to the activities of pharmaceutical companies in selling the new disorder. The expansion of the boundaries of mental disorder, partly through the broadening of earlier categories, was explored in two studies by AV Horwitz and JC Wakefield (2007; 2012), both underpinned by the idea of medicalisation, though only occasionally using the term. The first focused on the way in which normal sorrow has been reconfigured into depression; the second on how natural anxieties and fears have similarly been transformed so that normal, appropriate reactions have come to be defined as mental disorders and the individual pathologised.

The medicalisation of misery has also been analysed by general practitioner Christopher Dowrick and psychiatrist Allen Frances (2013), who argued that depression is being over-diagnosed and too many individuals put on drugs from which they will not benefit. Frances had been the head of the DSM-IV task force, and the subtitle of his book Saving Normal (2013) made his more recent stance explicit: An insider's revolt against out-of-control psychiatric diagnosis, DSM-5, big pharma, and the medicalization of ordinary life.

\section{Criticisms of the concept}

While many have found the concept of medicalisation useful, others have been more critical. Karen Ballard and Mary Ann Elston contended that the original concept was strongly associated with medical dominance and that 'this view of a docile lay populace, in thrall to expansionist medicine, has been challenged' (2005:228), a point reiterated by Rose (2007) in his critique. Ballard and Elson argued that there has been a decline in the trust of expert authority and present-day consumers are more active, sometimes encouraging medicalisation, sometimes resisting it. They further contended that some early accounts of medicalisation gave too much emphasis to medicine's imperialistic tendencies and underplayed its benefits. There are three issues. Do accounts of medicalisation assume a docile populace? Do such accounts, as Ballard and Elston claim, emphasise medical imperialism? And do they underplay medicine's benefits?

Patient passivity 
We can certainly find assumptions in analyses of medicalisation that patients are docile and powerless in the face of medical experts - what Helen Roberts (1985) discussing women called 'patient patients'. Yet equally we can find those who assume that, while doctors have considerable power and their domain has extended, many patients seek to question and resist medical power, including processes of medicalisation. Parsons certainly implied patient passivity: 'the combination of helplessness, lack of technical competence, and emotional disturbance make him a peculiarly vulnerable object for exploitation' (1951:445). Freidson however argued that there was a need for increased education of the public, and for lay participation in forming professional policy, calling for greater emphasis on clients' rights - a position endorsed by Zola. In contrast Illich argued that medicine takes away individual autonomy and undermines the capacity of individuals to cope with illness. Conrad, too, in his 1975 paper suggested that medical experts' views tended to dominate those of the public, but more recently he has listed instances of resistance to medicalisation (2007).

Certainly, while patient passivity still occurs, the description does not fit the more active and challenging role now often played by patients. A range of authors have emphasised the activism of patients talking of 'informed' or 'expert' patients, of the growth of consumerism, of patients' resistance to medical ideas and treatments, and how patients use new technologies like the internet to secure information, to demand particular treatments, and challenge medical ideas (Conrad 2007). Lay participation has also been increased by the incorporation of users into policy making bodies (sometimes a matter of lip service), and through user group activity, and strategies of patient engagement. Patients and patient pressure groups are becoming more active, sometimes challenging medicalisation, sometimes directly encouraging it. Ballard and Elston are therefore right to argue that frequently patients are not passive and are becoming less deferential, but patient activism is something analysts of medicalisation often emphasise. However, they are surely mistaken in suggesting that the concept necessarily assumes or requires patient passivity.

\section{Medical imperialism}

What of the criticism that medicalisation analysts tend to emphasise medical imperialism? Here we need to distinguish two uses of the term. First, it can be used to mean active empire-building by medical professionals. This is the sense in which it has been discussed so far, and how Phil Strong (1979) used it in his examination of professional imperialism. However, Strong seems to have read Illich's term medical colonisation as making an assertion of medical imperialism not just as an alternative to medicalisation. Consequently he conflated the two: "The thesis of "medical imperialism", that is of the increasing and illegitimate medicalization of the world, is one of most influential recent developments in the sociologies of deviance and 
medicine' (1979:199). Simon Williams, revisiting Strong's paper, repeated this conflation, defining the imperialist thesis as 'the increasing, and in large part, "illegitimate medicalisation" of the social world' (2001:137). This confounding is unfortunate, since medicalisation describes the expansion of the medical domain, whereas medical imperialism makes claims about its causes. Yet, as noted, those who initially developed the term medicalisation, including Illich, did not explain its occurrence in terms of medical empire-building.

A second interpretation of medical imperialism emphasises medicine's power as an institution, not empire-building by clinicians, locating medicine within the broader social context of industrial capitalist society and seeing its power as a product of its relation to other institutions. Such ideas, derived from political economy and macro-level analyses of the structure of power in advanced western societies, generate talk of 'health empires' and a 'medical-industrial complex'. The latter echoes the more familiar 'military-industrial complex' that refers to the tight relationships between government, armed forces and arms industry, an alliance regarded as powerful and potentially dangerous. Similarly the term medical-industrial complex, suggests a structure of power founded on a confluence of economic interests involving the medical profession, government, service providers, insurers, and medical technology manufacturers - a complex focused on making profits rather than putting the population's health at the forefront. Medicine is seen as part of a wider capitalist health empire extending well beyond the profession's activities. Influential in the 1970s (eg Navarro 1976), the approach encouraged talk of medical imperialism, and was also reflected in Illich's emphasis on industrialisation and economic growth as medicalisation's key causes. However, medical imperialism in either sense is not a necessary implication of the term medicalisation.

\section{The value of medicine}

Finally, there is the criticism that analysts of medicalisation downplay medicine's benefits. Certainly this was not true of Parsons, or of Freidson who in a well-known passage asserted 'Choice to consult cannot be forced; it must be attracted. The “good results" of medical practice with a sound foundation of knowledge, I believe, is one important source of attraction' (1970:21). Zola, too, though somewhat critical of medicalisation, talked of 'medicine's potential' (1972:500); and Conrad (1975) gave explicit attention to medicine's humanitarian benefits alongside his criticisms of transforming difficult, sometimes disruptive children into psychiatric patients. But Conrad was arguing against a particular instance of medicalisation, not critiquing medicine more generally. Further, as noted, some 1970s feminists similarly pointed to women's important gains from medicine, and more recently others have pointed to men's gains from the medicalisation of conditions such as impotence (Potts 2000) and male infertility (Barnes 2014) - all examples of 'good' medicalisation (Parens 2013). 
However, it was primarily Illich's forceful criticisms of medicine I suggest that led others to see the concept of medicalisation as critical of medicine more generally, even though his influence has by now largely waned. For example, Rose in his critique describes medicalisation as a 'cliché of critical social analysis' (2007:700), contending it has little analytical value:

The theme of medicalisation, implying the extension of medical authority beyond a legitimate boundary, is not much help in understanding how, why, or with what consequences these mutations have occurred. Medicalisation might be a useful neutral term to designate issues that have become part of the province of medicine. It might be a useful slogan for those who wish to dispute the legitimacy of that medical remit. But the term itself should not be taken as a description or an explanation, let alone a critique. Not an explanation for there is no dynamic of medicalisation, no implacable logic of medical entrepreneurship, no single motive of medical interests, that lies behind these various boundary renegotiations; not a description, for there are many important distinctions to be made here (2007:701).

Rose here rejects any explanation (or description) of medicalisation in terms of 'medical entrepreneurship' or a 'single motive of medical interests' and their 'implacable logic', even though such an explanation has rarely been widely espoused by analysts of medicialisation. Surprisingly Rose seems to overlook the careful empirical analyses of specific extensions of medicine that identify complex, often episodic, social processes underpinning medicalisation involving a range of actors. Indeed, he presents something of a caricature of research on medicalisation.

Rose's overriding objection to the term is that it can be read as suggesting that the extension of medical authority is not legitimate: 'It implies something suspect when a problem is created or annexed, in whole or in part, by the apparatus of medicine' (2007:700, my emphasis). The social historian, Roy Porter, also commented that, while the profession viewed the medical umbrella as benign, 'the term "the medicalization of society", used by critics, has a routinely negative ring' (1997:691), and both Strong (1979) and Williams (2001) talked of 'illegitimate medicalisation'. Rose, however, wants to exclude any negative connotations, arguing that medicalisation is only useful if it is a 'neutral term', indicating there is no place for doubting the legitimacy of particular instances of medicalisation. Yet questioning specific extensions of medicine's domain as illegitmate, sometimes successfully as with homosexuality, can be appropriate, and should not be read as questioning the value of much of medicine, or as a claim that all instances of medicalisation are unacceptable. It is essential to distinguish the evaluation of particular instances from any general critique of medicine. Indeed description and explanation, not critical evaluation, are often the prime aim of medicalisation research.

\section{Biomedicalisaton and pharmaceuticalisation}

An alternative approach has been to argue that the concept of medicalisation needs to be replaced. Adele Clarke and colleagues (2003), drawing on Foucauldian ideas, argued that there was a major shift in the US around 1985 from an earlier era of medicalisation to one better labelled biomedicalisation. This is their term 'for the increasingly complex, multisited, 
multidirectional processes of medicalization that today are being both extended and reconstituted through the emergent social forms and practices of a highly and increasingly technoscientific biomedicine' (2003:162). They contend that biomedicalisation involves five processes: (a) major political and economic shifts, including the development of the corporatised and privatised 'US biomedical technoservice complex, inc' (2003:166) (paralleling the medical-industrial complex); (b) 'a focus on health, risk and surveillance' (2003:171); (c) the 'technoscientization of biomedicine' (2003:173); (d) the transformation of biomedical knowledges; and (e) transformations of bodies and identities. This shift, they argue, is associated with a move from modernism to late or postmodernism, and demonstrates 'the mutual constitution of political economic, cultural, organizational, and technoscientific trends and processes' (2003:184, authors' emphasis).

Clarke et al point to important changes in medicine over the last thirty years, but their analysis can be challenged. First, it is not clear that the changes since 1985 are sufficient to demonstrate a major transformation in American medicine around this time. Historians, rightly, often demarcate significant periods of history, identifying important changes in thinking and behaviour, but Clarke et al's idea of a turning point around the mid-1980s is debateable. The authors' detailed charting in the paper and a subsequent book (2010) of differences between the eras of medicalisation and biomedicalisation in the US requires the selection of different labels to characterise features of the two eras, but these lack detailed justification. For example, under the category the 'technoscientization of biomedicine'; the period of medicalisation is characterised as 'Antibiotics and other new drugs', whereas for biomedicalisation it is described as 'pharmaceutical regimens' (2010:97). The choice of different labels implies a marked contrast in content, yet the authors rather present the claimed differences as self-evident. Many drugs used in the period 1945-1990, including many psychoactive drugs, involved pharmaceutical 'regimens'. Further one problem with their efforts to distinguish the two periods is that it yields an over-complex framework that tries to encompass too much. As Williams et al assert, biomedicalisation is a 'catch-all notion' (2012:2130), while Conrad comments the 'authors paint biomedicalization with such a broad brush that medicalization gets lost' (2013:202)

Second, their analysis raises questions about their use of the terms medicalisation and biomedicalisation as labels for specific eras of medicine (they later add an earlier period 'the rise of medicine' (2010)). Medicalisation refers to a process that can occur across time and place, indeed this is one of its attractions; it is not intended as a label for a particular period in medicine's development. We may wish to talk of biomedicine as a particular type of medicine, and apply that to a particular era, but it is unhelpful to use process terms like biomedicalisation to designate a specific era. The term may seem attractive, given its associations with Foucault's theoretical ideas and his focus on the body and biopower (see [1976]1978), but this is not in itself 
a justification for the addition of 'bio' to medicalisation. Of course we may use the new term to refer to certain distinctive changes in the character of medicine, but used in this way it is doing very different analytical work from the term medicalisation, which highlights the extension of medical activity, and the new term cannot be a substitute for the earlier one. Indeed, Bell and Figert's (2015) bracketing of the prefix 'bio' in their edited collection suggests some uncertainty about its use. What though of the term pharmaceuticalisation? Does this capture important changes that the concept of medicalisation does not? John Abraham defines it as 'the process by which social, behavioural or bodily conditions are treated or deemed to be in need of treatment, with medical drugs by doctors or patients' (2010:604). He also explicitly raises the question of whether pharmaceuticalisation can be subsumed under medicalisation - a position also articulated by Conrad who talks of 'pharmaceuticalization as a subset of medicalization and not as a competing concept' (2013:201). However, Abraham argues there are significant differences between them. One is that there can be shifts between treatment regimes in an already medicalised condition - say a shift from psychotherapy to drugs. Another is that there can be direct purchase of medicines without a prescription, with some prescription-only medicines becoming available over-the-counter. Yet a shift between therapeutic regimes does not in itself require the introduction of a new concept, and in the latter case a drug's legitimacy depends on medicine's imprimatur reflected in the common appellation 'medicines'.

Abraham identifies five factors driving pharmaceuticalisation: 'biomedicalism (including industry drug research, development and innovation); medicalization; industry drug promotion and marketing; consumerism; and the ideology or policy of the regulatory state' (2010:606). Certainly one of the concept's attractions is that it points to the growing use of pharmaceuticals and the industry's power in generating change. However, the pharmaceutical industry's role can still be emphasised without it, as Conrad $(2005 ; 2007 ; 2013)$ and others have done. While it is crucial to look at the activities of the industry, we do not need to parallel the term medicalisation with that of pharmaceuticalisation. And even if we accept the term has some uses (see Gabe et al 2012), it does not diminish the value of the earlier concept.

\section{The value of the concept}

There are two fundamental reasons why the term medicalisation is still of major value as a conceptual tool for sociological analyses of medicine and health and illness. First, it identifies an important process that is still occurring. Examining twentieth-century medicine, Porter commented: 'Medical interventions grew in all branches of life' (1997:692). The same has continued to be true in the early decades of the twenty-first century. Medicalisation is proceeding apace and continuing to 
transform everyday understandings of human behaviour, experiences and problems, notwithstanding the occasional efforts at demedicalisation, successful in the case of homosexuality (Spector 1977).

Consider the following examples. The DSM-5 (APA 2013) further extended the process noted earlier of characterising what were previously regarded either as misfortunes or matters of character as mental disorders, creating new disorders such as 'gambling disorder', 'hoarding disorder', 'binge eating disorder' and 'disruptive mood dysregulation disorder', and also lowered the thresholds of others, as with the removal of the bereavement exclusion clause from the criteria for major depressive disorder.. The new disorders can be viewed as a further extension of diagnostic cultures in psychiatry (Brinkmann 2016) that penetrate everyday life and transform understandings. Several factors encourage this shift. One is the pharmaceutical industry's activities in seeking to extend their markets across the world. Such processes of globalisation may involve the spread of the use of psychiatric categories and treatment from western to lower-income countries (see Conrad and Bergey 2014). Increasing consumerism, and patients' demand for medical help for problems they face, and the need under US health insurance arrangements for a diagnosis to be assigned if care or treatment is to be funded (Conrad 2013) also play an important role. Yet the result is that more individuals across the world are brought into the psychiatric fold and prescribed psychoactive medicines, deflecting attention away from features of society that often underpin such mental states and behaviours. Although many psychoactive medications are of dubious benefit (Kirsch 2009), their use is increasing rapidly (Busfield 2010)

And then there is the increasing use of medicines to try and reduce the risk of illness, by assessing the risks of an individual developing specific conditions and prescribing medicines to prevent this. Not only are more and more risks identified, but the thresholds of the bodily markers judged indicative of risks requiring intervention are frequently lowered, thereby encouraging the prescribing of drugs such as stimulants, statins, anti-hypertensives , and so forth, to many people often for long periods of time, if not life (Dumit 2012). This is despite the fact that the value of such medicines in preventing disease is strongly debated.

Another related area of medical expansion concerns obesity, which increases the risk of subsequent health problems, especially type 2 diabetes. Not only is obesity increasing in many countries, but it is also increasingly medicalised (Jutel 2006) and treated with medications or, in severe cases, bariatric surgery (Blackburn 2011) Indeed the American Medical Association (2013) has, controversially, now officially defined it as a disease. Yet medical interventions, even when effective, fail to deal with the factors underlying the growth in obesity in affluent societies, such as the activities of the food industry, that encourage 
and enable the consumption of high-calorie food, along with changes in the character of paid work and transport that lead to reductions in physical activity. It is politically easier to focus on holding individuals responsible for their condition blaming them for not controlling their diet or exercising enough, rather than, for instance, to regulate the behaviour of the large-scale corporations that produce unhealthy food.

There is also a continuing growth in biomedical enhancements such ascosmetic surgery in many countries, including South Korea, India, Brazil, Venezuela, and the US, where the largest number of procedures are carried out (ISAPS 2015), along with an increase in cosmetic tourism. Here again consumers actively encourage medicalisation. There is also a major expansion in the use of licit and illicit drugs to enhance physical and mental functioning, such as steroids in body building and sport, and drugs that encourage concentration and improve mental performance. Indeed, the domain of bodily and mental enhancement is a significant area of medical expansion (Sauter and Gerlinger 2014), though it does not routinely involve the application of labels of health and illness. Appearance and functioning may not be regarded as pathological, but in the highly consumerist cultures of affluent societies as something to be improved - a medicalisation of the body. However, the desirability of this expansion is highly debatable.

The second reason why medicalisation remains a key conceptual tool is because it draws attention to the social causes underpinning the extension of medicine's domain and to its impact. The causes, as we have seen, include the social, political and economic advantages and interests of a range of actors (Light 1995), including governments, pharmaceutical companies, patients and consumers, and medical professionals. The consequences are also wide-ranging and various and include the transformation of everyday understandings and behaviours. Yet viewing something in medical terms can, regrettably, lead to thinking about the individual to the exclusion of features of society and the social and economic inequalities that often underpin personal problems.

The way in which medicine can shape understandings and subjectivity was captured by Rose when he talked of how 'we have come to experience ourselves in fundamentally medical terms' (1994:69). It is ironic that Rose, whilst illuminating this penetration of medicine into everyday life, nonetheless suggested sociologists should abandon the concept of medicalisation. It is certainly correct that the term quite frequently has a 'negative ring' (Porter 1999:691), one reason for Rose's hostility to it, but this is not because medicine or medical professionals are viewed negatively overall, but because, as Conrad and others have long argued, defining a condition as an illness and adopting a medical approach can have major social consequences and close 
off alternatives. While it is clear that in some instances medicalisation can lead to important gains for individuals, in others the issue becomes one of the individual and the task to treat what is judged as their pathology, depoliticising the problem and largely ignoring the wider social and institutional context of individuals' physical and mental states and behaviour and the deficiencies of the society in which they live. Resources and priorities are devoted to medical interventions rather than to broader social and political improvements (Clark 2014)

Conclusion

I have argued that critics of the concept of medicalisation who assert its irrelevance or call for its abandonment are mistaken. The term, which like other sociological concepts has been interpreted in different ways, should not be read as necessarily assuming either passive patients, or empire-building by medical professionals, whether in alliance with corporations or not, though the activities of doctors and their enthusiasm for new technologies can contribute to instances of medicalisation. Nor should it be read as making some generalised attack on medicine, which can and often does ameliorate individuals' health problems. The criticisms by medicalisation analysts, if and when they are made, are of specific instances of medicalisation not of medicine more generally. I have also argued that for different reasons neither biomedicalisation nor pharmaceuticalisation provide adequate alternatives. The frequent use of the term medicalisation by sociologists, historians, and clinicians demonstrates its value as a conceptual tool in identifying, describing, seeking to understand and explain and sometimes questioning, the continuing extensions (and less frequent retrenchments) of medical activity. Much of this research involves identifying and analysing new domains of medicalisation; some the development of new ways of understanding the factors contributing to medicalisation, as with the analyses linking medicalisation and globalisation, and also of its consequences, as with the expanding work on diagnostic cultures and subjectivities. The concept of medicalisation still has a vibrant and crucial place in sociological analyses of medicine and of the changing culture of late-modern societies.

\section{References}

Abraham, J (2010) 'Pharmaceuticalization of society in context: theoretical, empirical and health dimensions', Sociology, 44:603-22.

Allen H (1987) Justice Unbalanced, Milton Keynes: Open University Press.

AMA (2013) 'AMA adopts new policies on second day of voting at annual meeting', Press Release, American Medical Association, June 18. 
APA (2013) Diagnostic and Statistical Manual of Mental Disorders, fifth edition, Washington: American Psychiatric Association.

Armstrong D (1983) The Political Anatomy of the Body, Cambridge: Cambridge University Press.

Ballard K and Elston M A (2005) 'Medicalisation: a multi-dimensional concept' Social Theory \& Health, 3:228-41.

Barker KK (1998) 'A ship upon a stormy sea: the medicalization of pregnancy’ Social Science \& Medicine, 47:1067-76.

Barnes L (2014) Conceiving Masculinity: Male infertility, medicine, and identity, Philadelphia: Temple University Press.

Barrett M and Roberts H (1978) 'Doctors and their patients', in B Smart and C Smart (eds) Women, Sexuality and Social Control, London: Routledge.

Bell AV (2009) 'It's way out of my league: low-income women's experiences of medicalized infertility', Gender \& Society, 23:688-709.

Bell SE (1987) 'Changing ideas: The medicalization of the menopause', Social Science \& Medicine, 24:535-42.

Bell SE and Figert AE (eds) (2015) Reimagining (Bio)medicalization, Pharmaceuticals and Genetics, New York: Routledge.

Blackburn GL (2011) 'Medicalizing obesity’. AMA Journal of Ethics, 13:890-95.

Brinkmann S (2016) Diagnostic Cultures: a cultural approach to the pathologisation of modern life, London: Routledge.

Busfield J (2010) ““A pill for every ill”: explaining the expansion in medicine use' Social Science and Medicine, 70:934-41.

Caplan PJ, McCurdy-Myers J and Gans M (1992) 'Should “premenstrual syndrome”be called a psychiatric abnormality?' Feminism \& Psychology 2:27-44.

Clark J (2014) 'Medicalization of global health 1: Has the global health agenda become too medicalized?' Global Health Action, 7:23998.

Clarke AE, Shim JK, Mamo L et al (2003) 'Biomedicalization: technoscientific transformations of health, illness, and US biomedicine', American Sociological Review, 68:161-94.

Clarke AE, Shim JK, Mamo L et al (eds) (2010) Biomedicalization: Technoscience, health, and illness in the US, Durham: Duke University Press.

Conrad, P (1975) 'The discovery of hyperkinesis', Social Problems, 12:12-21.

Conrad P (1992) 'Medicalization and social control', Annual Review of Sociology, 18:209-32.

Conrad P (2005) 'The shifting engines of medicalization’, Journal of Health and Social Behavior, 46:3-14.

Conrad P (2007) The Medicalization of Society, Baltimore: John Hopkins.

Conrad P (2013) 'Medicalization: changing contours, characteristics, and contexts', in W Cockerham (ed) Medical Sociology on the Move, New York: Springer.

Conrad P and Barker KK (2010) 'The social construction of illness: Key insights and policy implications', Journal of Health and Social Behavior, 5(S):S67-S79.

Conrad P and Bergey MR 'The impending globalizetion of ADHD: Notes on the expansion and growth of a medicalized disorder', Social Science and Medicine, 122:31-43. 
Conrad P and Potter D (2000) 'From hyperactive children to ADHD adults: observations of the expansion of medical categories' Social Problems, 47:559-82.

Conrad P and Schneider JW (1980) Deviance and Medicalization, St Louis: Mosby.

Dowrick C and Frances A (2013) 'Medicalising unhappiness', BMJ, 347:f7140.

Dumit J (2012) Drugs for Life, Durham: Duke University Press.

Ehrenreich B and English D (1972) Witches, Midwives and Nurses, New York: Feminist Press.

Ehrenreich B and English D (1973) Complaints and Disorders, London: Writers and Readers Cooperative.

Ehrenreich B and English D (1979) For Her Own Good, London: Pluto.

Foucault M ([1963]1973) The Birth of the Clinic, London:Tavistock.

Foucault, M (([1974]2000) 'The birth of social medicine', in JD Faubion (ed) Essential Works of Michel Foucault, 1954-1984, Vol 3: Power. New York: New Press.

Foucault M ([1976]1978) The History of Sexuality, Volume 1, London: Allen Lane.

Foucault M (1991) 'On governmentality’ in G Burchell, C Gordon and P Miller (eds) On Foucault, London Harvester Wheatsheaf.

Frances A (2013) Saving Normal, New York: HarperCollins.

Freidson E (1970) The Profession of Medicine, New York: Dodd, Mead.

Gabe J, Williams S, Martin P and Coveney C, (2015) 'Introduction, Pharmaceuticals and society: Power, promises and prospects', Social Science \& Medicine, 131:193-98.

Horwitz AV and Wakefield JC (2007) The Loss of Sadness: How psychiatry transformed normal sorrow into depressive disorder, New York: Oxford University Press.

Horwitz AV and Wakefield JC (2012) All We Have to Fear: Psychiatry's transformation of natural anxieties into mental disorders, New York: Oxford University Press.

ISAPS (2015) Global Statistics, Hanover, International Society for Aesthetic Plastic Surgery.

Illich I (1975) Medical Nemesis, London: Marion Boyars.

Jutel A (2006) 'The emergence of overweight as a disease entity: measuring up normality' Social Science \& Medicine, 63:2268-76.

Kirsch 1 (2009) The Emperor's New Drugs, London: Bodley Head.

Lahiri-Dutt (2015) 'Medicalising menstruation: a feminist critiques of the political economy of menstrual hygiene in South Asia', Gender, Place \& Culture, 22: 1158-76.

Lane C (2007) Shyness: How normal behaviour became a sickness, New Haven; Yale University Press.

Light D (1995) 'Countervailing powers: a framework for professions in transition', in T Johnson, G Larkin and M Saks (eds) Health Professions and the State in Europe. London: Routledge. 
Navarro V (1976) Medicine under Capitalism, New York: Prodist.

Oakley A (1984) The Captured Womb, Oxford: Blackwell.

Parens E (2013) 'On good and bad forms of medicalization', Bioethics, 27:28-35.

Parsons T (1951) The Social System, London: Routledge.

Pitts J (1968) 'Social control: the concept', in DL Sills (ed) International Encyclopaedia of the Social Sciences, New York: Macmillan

Porter R (1999) The Greatest Benefit to Mankind, London: Fontana.

Potts A (2000) "”The essence of the hard on"” Men and Masculinities, 3:85-103.

Riessman CK (1983) 'Women and medicalization: A new perspective’, Social Policy, 14:3-18.

Robert H (1985) The Patient Patients, London: Pandora Press.

Rose N (1986) 'Psychiatry: the discipline of mental health', in P Miller and N Rose (eds) The Power of Psychiatry, Cambridge: Polity.

Rose N (1994) 'Medicine, history and the present', in C Jones and R Porter (eds) Reassessing Foucault, London: Routledge.

Rose N (2007) ‘Beyond medicalisation', Lancet, 369:700-03.

Sauter A and Gerlinger K (2014) The Pharmacologically Improved Human, Berlin: TAB.

Scott S (2007) Shyness and Society, Basingstoke: Palgrave.

Spector M (1977) ‘Legitimising homosexuality’ Society, 14:52-6.

Strong PM (1979) 'Sociological imperialism and the profession of medicine', Social Science \& Medicine, 13A:199-215.

Szasz T (1961) The Myth of Mental Illness, New York: Hoerber-Harper

William S (2001) 'Sociological imperialism and the profession of medicine revisited', Sociology of Health \& Illness, 23:13558

William S, Gabe J and Martin P (2012) 'The pharmaceuticalisation of society? A framework for analysis', Sociology of Health \& Illness, 33:710-25.

Young A (1995) The Harmony of Illusions, Princeton: Princeton University Press.

Zola I (1972) 'Medicine as an institution of social control', Sociological Review, 20:487-504. 